\title{
A longitudinal study of near-miss and maternal mortality at a tertiary centre in rural Uttarakhand: addressing the fourth delay
}

\author{
Mishu Mangla, Ruchira Nautiyal*, Deepmala
}

Department of Obstetrics and Gynecology, Himalayan Institute of Medical Sciences, Jollygrant, Dehradun, Uttarakhand, India

Received: 29 May 2019

Accepted: 09 July 2019

*Correspondence:

Dr. Ruchira Nautiyal,

E-mail: deepak10.4u@gmail.com

Copyright: (c) the author(s), publisher and licensee Medip Academy. This is an open-access article distributed under the terms of the Creative Commons Attribution Non-Commercial License, which permits unrestricted non-commercial use, distribution, and reproduction in any medium, provided the original work is properly cited.

\section{ABSTRACT}

Background: India is a signatory of the sustainable development goals and is committed to reduce the maternal mortality ratio to less than 70 per lakh live births. Review of maternal deaths and near miss cases is a very important step towards achieving this aim.

Methods: A prospective observational study was carried out in a tertiary care centre in rural Uttarakhand for a period of one and half year using WHO criteria for maternal near-miss, in an attempt to assess the quality of obstetric care in the region and to identify the possible delays leading to this.

Results: Haemorrhage was the most common cause leading to severe maternal outcome, followed by early pregnancy complications and hypertensive disorders of pregnancy. The mortality index was $15 \%$ and maternal near miss to mortality ratio was 7:1. We could identify some type of delay in at least $70 \%$ of near miss and mortality cases. Although delay in seeking healthcare was the most common, lack of community participation was identified as an important fourth delay.

Conclusions: For substantive reduction of maternal mortality in this region of Uttarakhand, the main action needed is strengthening of primary health care, educating the patients regarding warning signs of pregnancy and strengthening the social status of women in society, increasing community support in women health care.

Keywords: Delays in health care, Maternal death, Maternal mortality, Near miss, Rural Uttarakhand, Severe maternal morbidity

\section{INTRODUCTION}

India is a signatory to the sustainable development goals, which targets to reduce the global maternal mortality ratio to less than 70/lakh live births. ${ }^{1}$ However, the present scenario makes this target look very difficult to achieve. At the country level, Nigeria and India accounted for one third of all maternal deaths worldwide in $2015 .^{2}$

The maternal mortality of India is presently 130/100,000 live births, although showing a large regional variation. ${ }^{3}$
It is 300/lakh live births for Assam and 67/lakh live births in Kerala.

Maternal mortality is a vital indicator in the assessment of health care services of any country. A maternal nearmiss event or severe acute maternal morbidity has been defined by the WHO as 'a woman who nearly died but survived a complication that occurred during pregnancy, childbirth or within 42 days of termination of pregnancy. Near miss cases have almost same pathophysiology as maternal mortality. ${ }^{4}$ As the absolute number of maternal deaths at any health centre may be very few, a study of 
near miss cases can serve as a surrogate marker to assess the quality of maternal health care at any centre. It has additional advantages of offering a comparatively large number of cases for analysis, woman herself being the source of information as well as having a better acceptability by institutions and individuals, as death was prevented. An accurate reporting of all cases of maternal mortality and near miss is very important, to identify strengths and deficiencies of health care system. To the best of our knowledge, there are presently no such studies from Uttarakhand.

The objective of the present study was to analyse all women with severe maternal outcome admitted at our tertiary care centre to assess the quality of maternal health care services and to determine the lacunae or levels of delays in health care system in this region using the WHO Near-Miss Approach 2011. ${ }^{4}$

\section{METHODS}

This was a longitudinal study conducted in the department of Obstetrics and Gynaecology, Himalayan Institute of Medical Sciences, Jolly Grant from October 2016 to March 2018, i.e. a period of 18 months.

Himalayan Institute of Medical Sciences is a 1000 bedded multi-speciality teaching hospital located in rural Uttarakhand. It serves as a referral centre for the neighbouring regions of the state as well as eastern UttarPradesh and even far off regions. Apart from routine obstetrics, it offers a comprehensive emergency and intensive care facilities to pregnant females. The Obstetrics and Gynaecology department consists of 11 consultants, 16 residents, interns and other supportive staff. All pregnant or post-partum females admitted in the obstetrics ward or intensive care unit of the hospital from October 2016 to March 2018 formed the source population while the study population included women who either died or suffered a maternal near miss from pregnancy, delivery or puerperal complication based on WHO criteria. ${ }^{4}$

\section{The definition of terms used to define maternal health is as follows}

- Maternal near miss (MNM) - A woman who nearly died but survived a complication that occurred during pregnancy, childbirth or within 42 days of termination of pregnancy

- Maternal death (MD) - The death of a woman while pregnant or within 42 days of termination of pregnancy or its management, but not from accidental or incidental causes

- Live birth (LB) - Birth of an offspring, which breathes or shows evidence of life.

- Severe maternal outcome (SMO) refers to a lifethreatening condition (i.e. organ dysfunction), including all maternal deaths and maternal near-miss cases
- Severe maternal outcome ratio (SMOR) refers to the number of women with life-threatening conditions $(\mathrm{MNM}+\mathrm{MD})$ per 1000 live births (LB). This indicator gives an estimate of the amount of care and resources that would be needed in an area or facility $[\mathrm{SMOR}=(\mathrm{MNM}+\mathrm{MD}) / \mathrm{LB}]$

- $\quad$ SMO 12- Cases presenting with organ dysfunction or maternal death within 12 hours of hospital stay

- MNM ratio (MNMR) - The number of maternal near-miss cases per 1000 live births $(\mathrm{MNMR}=$ MNM/LB)

- Maternal near-miss mortality ratio (MNM: MD) refers to the ratio between maternal near miss cases and maternal deaths

- Mortality index - The number of maternal deaths divided by the number of women with lifethreatening conditions expressed as a percentage [MI $=\mathrm{MD} /(\mathrm{MNM}+\mathrm{MD})]$.

Sampling approach used for recruiting the patients was exhaustive. All pregnant females or women in the puerperal period, admitted in obstetrics ward, emergency department, or ICU, who either died or survived a near miss event as per WHO criteria were included in the study. The study period was 18 months, from October 2016 to March 2018. A monthly review of maternal mortality and near miss cases is conducted in the department of obstetrics and gynaecology, to identify and discuss the possible delays and pitfalls in the management of such cases. The principal investigator collected the data from such record with the help of junior residents. The study Performa used was WHO maternal near miss tool. ${ }^{4}$ The data extracted included the demographic and reproductive data, markers of organ dysfunction predisposing to maternal mortality or near miss. Primary and secondary causes leading to maternal near miss or mortality were recorded. We also tried to explore any patient related, administrative or medical facility related delay that led to severe maternal outcome. Informed consent from the patient was not required as there was no personal contact with the patient and the study only consisted of analysis of case records. Permission was obtained from the institutional ethical committee for the publication of data.

\section{Statistical analysis}

The data thus collected was entered into excel sheet and analysed using SPSS version 20. Results were expressed as frequency and percentage and correlation was used to explore relationship. The $\mathrm{p}$ value of $<0.05$ was considered as significant.

\section{RESULTS}

During the study period, there were 2398 deliveries, 2293 live births and 105 stillbirths or intrauterine foetal demise. 80 women with severe maternal outcome were recorded, 68 had a near miss event while 12 women died because of pregnancy or puerperal complication. The 
severe maternal outcome incidence ratio was calculated to be $34.88 / 1000$ live births, maternal near miss incidence of 29.6/1000 LB and maternal mortality rate of 523.3 per lakh live births. The mortality index was $15 \%$ and maternal near miss to mortality ratio was $7: 1$. Out of all women who suffered a severe maternal outcome, $87.5 \%$ were referred cases (Table 1).

Table 1: Severe maternal outcome and maternal near miss indicators at HIMS, Dehradun.

\begin{tabular}{|ll|}
\hline Outcome & Near-miss indicators \\
\hline $\begin{array}{l}\text { Total number of live births } \\
\text { during study period }\end{array}$ & 2293 \\
\hline SMOs cases & 80 \\
\hline Maternal deaths & 12 \\
\hline Near miss cases & 68 \\
\hline Near miss indicators & 34.88 \\
\hline $\begin{array}{l}\text { Severe maternal outcome } \\
\text { ratio (/1000 live births) }\end{array}$ & 29.6 \\
\hline $\begin{array}{l}\text { Maternal near miss ratio } \\
\text { (/1000 LB) }\end{array}$ & $7: 1$ \\
\hline $\begin{array}{l}\text { Maternal near miss: } \\
\text { mortality ratio }\end{array}$ & $15 \%$ \\
\hline Mortality index & 72 \\
\hline Hospital access indicators & $90 \%$ \\
\hline SMO 12 (n) & $16.66 \%$ \\
\hline $\begin{array}{l}\text { Proportion of SMO 12 cases } \\
\text { among all SMO cases }\end{array}$ & 9 \\
\hline $\begin{array}{l}\text { Proportion of SMO 12 cases } \\
\text { coming from other health } \\
\text { facilities }\end{array}$ & $87.5 \%$ \\
\hline SMO 12 mortality index & 9 \\
\hline $\begin{array}{l}\text { Intrahospital care } \\
\text { Intrahospital SMO cases } \\
\text { (number) }\end{array}$ & $\begin{array}{l}\text { Intrahospital SMO rate (per } \\
\text { 1000 live births) }\end{array}$ \\
\hline Intrahospital mortality index & 0 \\
\hline
\end{tabular}

The distribution of primary cause of severe maternal outcome is shown in Figure 1. Haemorrhage was the most common cause leading to severe maternal outcome, contributing to $67.5 \%$ of all cases. Although post-partum haemorrhage was the major contributor in patients with haemorrhage, there were five cases of rupture uterus, two with morbidly adherent placenta and two patients with scar dehiscence. Early pregnancy complications (including ruptured ectopic) were another very important cause of severe maternal outcome. They contributed a $22.5 \%$ of all cases. Hypertensive disorders and medical disorders in pregnancy were causative in $16.25 \%$ and $8.75 \%$ respectively (Figure 1 ).

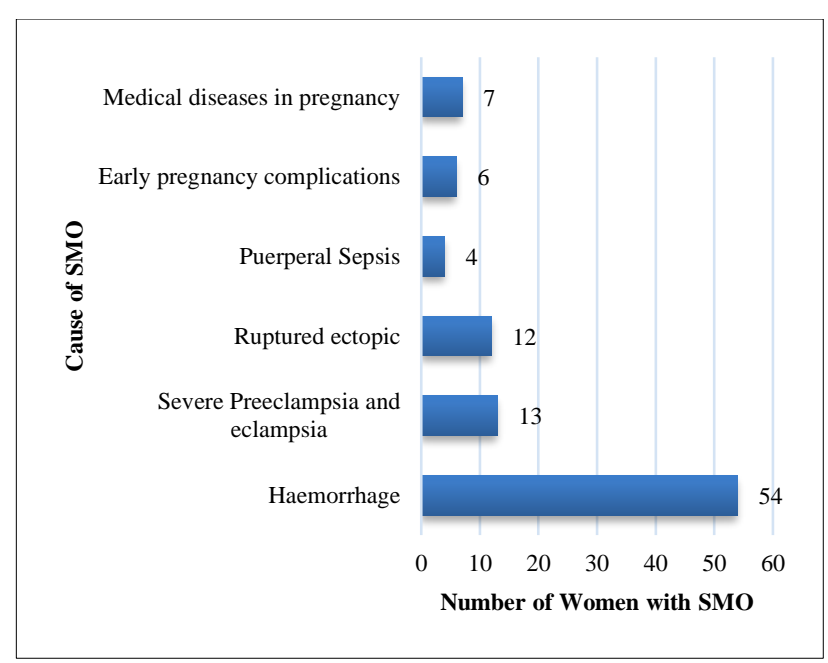

Figure 1: Causes of severe maternal outcome.

There were 12 maternal deaths during the study period. Most common cause of maternal mortality at our centre was haemorrhage $(46 \%)$. Hypertensive diseases of pregnancy, puerperal sepsis and medical disorders in pregnancy contributed about $15 \%$ each. There were two deaths due to septic abortion. The causes of mortality and near miss were almost similar. Among the primary causes of maternal mortality, hypertensive diseases including eclampsia had the highest mortality index (15.4\%), closely followed by haemorrhage $(11.11 \%)$.

27 patients required emergency peri-partum hysterectomy. The most common reason for peri-partum hysterectomy was atonic post-partum haemorrhage $(18 / 27)$, not responsive to medical management or conservative measures. 4 patients had morbidly adherent placenta, 2 scar pregnancies leading to torrential haemorrhage, 2 rupture uterus and 1 due to puerperal sepsis. Five patients had to undergo re-exploration due to hemoperitoneum.

Considering only the intra hospital cases, 4 patients developed a near miss event, two patients had torrential bleed at the time of suction evacuation, which needed emergency hysterectomy. These were later confirmed to be scar pregnancy. One patient with chronic liver disease developed severe atonic PPH and stillbirth. One patient had massive atonic post-partum haemorrhage, unresponsive to medical management thus needing hysterectomy. $90 \%$ of all cases with severe maternal outcome had organ dysfunction within 12 hours of hospital stay. $87.5 \%$ of all SMO 12 cases were referred from other health centres. There were no intra hospital cases of maternal mortality (Table 2).

We could identify some type of delay in at least $70 \%$ of near miss and mortality cases. Delay in decision to seek care (delay 1) and delay at the point of access to care (delay 2) were the most common delays found in about $50 \%$ of patients and delay in receiving adequate treatment (delay 3) was found in $15 \%$. Another 
interesting finding of our study was another type of delay, which was due to lack of community support in accepting the responsibility of taking care of basic rights of woman such as family planning and safe abortion practices.

Table 2: Levels of delay identified in maternal mortality and near miss cases.

\begin{tabular}{|c|c|c|c|}
\hline \multirow[b]{2}{*}{ Delays } & \multicolumn{3}{|c|}{ Level of health service in which delay was identified } \\
\hline & Primary health care level & Secondary health care & Tertiary health care \\
\hline Absence of blood products & $90 \%$ & $25 \%$ & $5 \%$ \\
\hline $\begin{array}{l}\text { Lack of medication: magnesium } \\
\text { sulphate, antibiotics, vasoactive } \\
\text { drugs, uterotonic }\end{array}$ & $60 \%$ & $10 \%$ & - \\
\hline $\begin{array}{l}\text { Difficulty in communicating } \\
\text { between hospital and regulatory } \\
\text { centre }\end{array}$ & $50 \%$ & $18 \%$ & - \\
\hline Lack of trained staff & $85 \%$ & $18 \%$ & $2 \%$ \\
\hline Delay in case referral/transfer & $60 \%$ & & \\
\hline Delay in diagnosis & $65 \%$ & $25 \%$ & $10 \%$ \\
\hline Delay in starting treatment & $46 \%$ & $15 \%$ & $5 \%$ \\
\hline Improper patient management & $26 \%$ & $25 \%$ & $15 \%$ \\
\hline
\end{tabular}

NOTE- The categories are not mutually exclusive.

\section{DISCUSSION}

Although India has made a significant progress towards reaching the millennium development goals, there is still an urgent need to make quality maternal and child health care facilities accessible especially to populations in the rural regions. ${ }^{5}$ Uttarakhand is a state with difficult terrain, steep gradient and adverse climatic conditions. Our study is one of the very few studies, which has evaluated the burden of maternal mortality and near miss cases in rural Uttarakhand. The present study also shows the gaps and strengths of a tertiary health care centre in rural Uttarakhand.

The maternal mortality rate of 523.3 per lakh live births, at this centre, is much higher than the national average of 174 per lakh live births. The main reason for this being the large number of complicated cases being referred here. This is the main referral care centre of Uttarakhand receiving referred cases not only from Uttarakhand but also from adjoining states of Haryana, Eastern Uttar Pradesh and Himachal Pradesh. Majority of patients are referred at a late stage when they are already in a stage that is largely irreversible.

The maternal near miss incidence of $29.6 / 1000 \mathrm{LB}$ and severe maternal outcome incidence ratio of $34.88 / 1000$ live births is much higher as compared other parts of the country. ${ }^{6,7}$ Although some middle- and low-income countries have reported rates as high as 75-100/1000 LB. ${ }^{8,9}$ The high maternal near miss incidence could be due to the fact that only a few hospitals in rural Uttarakhand provide comprehensive emergency obstetric care. Although there has been a significant increase in the number of institutional deliveries, still a large number of deliveries occur at home, in which traditional birth attendants who are not properly skilled, manage. They refer women only at late stage when the women develop a severe complication or impending death. This fact can also be appreciated by the low number of uncomplicated pregnancies managed at the institution during the study period. The major bulk, about $87.5 \%$ of all women with severe maternal outcome were referred cases who had delivered either at home or at peripheral health institutions. Majority of near miss occurred before arrival at the hospital.

Severe maternal outcome within 24 hours, SMO 12, the women presenting with organ dysfunction or other criteria of near miss within 12 hours of hospital stay provides an idea that these women came to the health facility at a very stage. These are largely due to first and second delay. $90 \%$ of all SMO cases at our centre had organ dysfunction within 12 hours of stay (Table 1). This clearly shows that women referred here are already in bad shape. The reasons may be many. The terrain of Uttarakhand is hilly, and some of the remote areas are cut off from city contact especially during the winter season. Heavy snowfall and lack of means of communication make these areas largely inaccessible. The low level of education and inequality in the social status of women makes their condition further more vulnerable. The peripheral health institutions do not have access to blood and blood component therapy. Although the government has taken efforts to improve health care facilities and even setting up tertiary health centres in this region, but they suffer from lack of manpower.

Worldwide the major causes of maternal mortality and near miss is hypertensive disorders, obstetric haemorrhage, sepsis and obstructed labour. ${ }^{10-12}$ The most 
common primary cause of both maternal mortality and near miss at our centre was post-partum haemorrhage followed by hypertensive disorders of pregnancy including eclampsia. This observation was similar to many other studies in the past. ${ }^{13}$ Complications due to obstetric haemorrhage, if identified in time are largely preventable. Non-availability of blood and blood products, especially at rural regions is another important contributing factor.

An important observation was that there are certain complications that have shown a sudden increase in frequency in our study as compared to previous studies. These are rupture uterus, scar dehiscence, scar pregnancy and morbidly adherent placenta. These are largely secondary to an increase in patients in whom the previous delivery was by caesarean section. The increasing rate of caesarean section is alarming, as this is fast emerging an important cause of morbidity in future. Previously the major contributor to obstetric haemorrhage was Postpartum haemorrhage, now there is a alarming increase in early pregnancy haemorrhage which can be pretty difficult to control with conservative measures.

The three-delay model was largely successful in assessing the levels of delay in health care facilities. Delays in seeking health services, refusal to treatment, and unsafe abortion due to both social and educational backwardness were the predominant reasons for delay in decision to seek care (delay 1). Difficulty in gaining access to antenatal care due to geographical Difficulties or problems with transportation to city/ hospital delay in accessing adequate care (delay 2). The poor quality of essential and emergency obstetric services mainly at the primary and secondary health care level $\mathrm{I}$ is responsible for the third delay, delay in receiving adequate treatment (delay 3). Lack of availability of blood and blood products, basic medicines like magnesium sulphate and prostaglandins is contributory. Another important delay we found in our study was failure of the community to take the responsibility of women's health (delay 4). ${ }^{13}$ Women are not given a right to decide about their fertility and family planning options. Unwanted pregnancy and unsafe and repeated abortions both are a major factor adversely affecting woman's health and later contributing to morbidity. Low social status of women and easy acceptance of maternal death are other factors discouraging women from approaching health care facilities. Although government has taken numerous steps to look into these issues, but much still needs to be done.

\section{CONCLUSION}

We infer that for substantive reduction of maternal mortality in this region of Uttarakhand, the main action needed is strengthening of primary health care, educating the patients regarding warning signs of pregnancy, and providing better means of transport in the form of motor cycle or helicopter ambulances. Birth attendants and doctors at primary and secondary health centres should refer the patients at an early stage when still the woman is in reversible stage. Strengthening the social status of women in society, increasing community support in women health care and educating women and making them self-dependant are other factors that could potentially decrease maternal near miss and mortality.

The present study is probably the first of its kind in Uttarakhand, which provides an overview of maternal health services in the region. However, the present study had certain limitations. Firstly, as only the patients admitted in this hospital were studied, this would not be a true reflection of the state as a whole. Secondly, the study period defined by WHO to define near miss is upto 42 days postpartum, but our study was only limited to the time period for which the patient was admitted to our hospital. Any patient who developed severe maternal outcome beyond their hospital stay and visiting other health care facilities could not be included in the study.

Funding: No funding sources

Conflict of interest: None declared

Ethical approval: The study was approved by the Institutional Ethics Committee

\section{REFERENCES}

1. World Health Organization World Health Statistics 2016: Monitoring Health for the SDGs, Sustainable Development Goals. 2016. Available at: http://www.who.int/gho/publications/world_health_s tatistics/2016/EN_WHS2016_TOC.pdf?ua=1

2. World Health Organization. Trends in maternal mortality: 1990 to 2015: estimates by WHO, UNICEF, UNFPA, World Bank Group and the United Nations Population Division. Geneva: World Health Organization; 2015. Available at: http://apps.who.int/iris/bitstream/10665/194254/1/97 89241565141_eng.pdf?ua=1

3. Parmar NT, Parmar AG, Mazumdar VS. Incidence of maternal "Near-miss" events in a tertiary care hospital of central Gujarat India. J Obstet Gynaecol India. 2016;66:315-20.

4. Say L, Souza JP, Pattinson RC. WHO working group on maternal mortality and morbidity classifications. Maternal near misses towards a standard tool for monitoring the quality of maternal health care. Best Pract Res Clin Obstet Gynecol. 2009;23(3):375-88.

5. Ministry of Statistics and Programme Implementation. Millennium Development Goals India Country Report 2015. New Delhi: Government of India; 2015.

6. Bansal M, Lagoo J, Pujari K. Study of near miss cases in obstetrics and maternal mortality in Bastar, Chhattisgarh, India. Int J Reprod Contracept Obstet Gynecol. 2016;5:620-3.

7. Rathod AD, Chavan RP, Bhagat V, Pajai S, Padmawar A, Thool P. Analysis of near-miss and maternal mortality at tertiary referral centre of rural 
India. J Obstetrics Gynaecol India. 2016;66(Suppl 1):295-300.

8. Gebrehiwot Y, Tewolde BT. Improving maternity care in Ethiopia through facility based review of maternal deaths and near misses. Int $\mathbf{J}$ Gynecol Obstet. 2014;127:S29-S34.

9. Berhane G, Gessessew A, Roosmalen JV. Obstetric near miss and maternal death: the case of Ayder teaching hospital, Mekelle, Ethiopia. Ethiopian J Reproduct Health. 2012;6(1):56-63.

10. Roost M, Altamirano VC, Liljestrand J, Essen B. Does antenatal care facilitate utilization of emergency obstetric care? A case-referent study of near-miss morbidity in Bolivia. Acta Obstet Gynecol Scand. 2010;89(3):335-42.

11. Ghazal-Aswad S, Badrinath P, Sidky I, Safi TH, Gargash H, Abdul-Razak Y, et al. Severe acute maternal morbidity in a high-income developing multiethnic country. Maternal Child Health J. 2013;17(3):399-404.

12. Tallapureddy S, Velagaleti R, Palutla H, Satti CV. "Near-Miss" Obstetric events and maternal mortality in a Tertiary Care Hospital. Indian J Public Health. 2017;61(4):305-8.

13. MacDonald T, Jackson S, Charles MC. The fourth delay and community-driven solutions to reduce maternal mortality in rural Haiti: a community-based action research study. BMC Pregnancy Childbirth. 2018;18:254.

Cite this article as: Mangla M, Nautiyal R, Deepmala. A longitudinal study of near-miss and maternal mortality at a tertiary centre in rural Uttarakhand: addressing the fourth delay. Int J Reprod Contracept Obstet Gynecol. 2019;8:3223-8. 